\title{
A review on the bio-functional roles of phospholipids from marine resources
}

\author{
1,*Haq, M. and ${ }^{2}$ Suraiya, S. \\ ${ }^{I}$ Department of Fisheries and Marine Bioscience, Jashore University of Science and Technology, Jashore \\ 7408, Bangladesh \\ ${ }^{2}$ Department of Fisheries and Marine Bioscience, Bangabandhu Sheikh Mujibur Rahman Science and \\ Technology University, Gopalganj 8100, Bangladesh
}

\author{
Article history: \\ Received: 20 November 2020 \\ Received in revised form: 20 \\ January 2021 \\ Accepted: 2 April 2021 \\ Available Online: 25 July \\ 2021
}

Keywords:

Marine phospholipids, Omega-3 polyunsaturated fatty acids,

Biological and nutritional functions

DOI:

https://doi.org/10.26656/fr.2017.5(5).677

\begin{abstract}
Marine phospholipids (PLs) rich in $\omega-3$ polyunsaturated fatty acids ( $\omega-3$ PUFAs) have drawn keen interest recently among researchers and consumers and could be assumed as a "miracle drug". Substantial amount of EPA and DHA, amazing and unique chemical properties and super bio-functional activities of marine PLs make it superior compared to terrestrial PLs, which lack long chain $\omega$-3 PUFAs. Many comparative studies revealed that marine PLs showed higher health beneficial activities compared to PLs obtained from land sources. Marine PLs are not only beneficial in containing a high amount of $\omega-3$ PUFAs but also in absorbing and assimilating $\omega-3$ PUFAs in different tissues. Synergistic effects of PL compounds and $\omega-3$ PUFAs in marine PLs showed super bio-functional performances like anti-atherosis and cardioprotective, anti-inflammatory, neuroprotective, immunological, and liver functions. A number of in vivo and in vitro studies on the administration of marine PLs extracted from fishes, mollusks, crustaceans, echinoderms reduced triacylglycerol (TAG) level and enhanced cardioprotective functions, demonstrated anti-inflammatory activity, reduced cell proliferation and tumor, increased cognitive functions and memory, and prevented hepatic damages. Therefore, this review paper provides detailed accounts on the present research status of critical biological and nutritional functions of marine $\omega-3$ PUFAs rich phospholipids focusing on the origin, animal models, treatment, and roles.
\end{abstract}

\section{Introduction}

Phospholipids (PLs) are a group of amphiphilic lipids where a glycerol unit is attached with two fatty acids and a phosphate group is esterified to an organic molecule such as choline, serine, ethanolamine and inositol. Thus, the major PLs develop their names as phosphatidylcholine (PC), phosphatidylserine (PS) phosphatidylethanolamine (PE), and phosphatidylinositol (PI). PLs derive an amphiphile nature by containing a negatively charged phosphate group and glycerol at the head part which acts as hydrophilic and containing 2 long-chain fatty acids at the tail part that are hydrophobic and avoid water interactions. Marine PLs are defined as PLs derived from marine organisms and characterized by the presence of $\omega-3$ long chain PUFAs. Marine PLs are unique and different from PLs derived from plants and vegetables because of their long chain $\omega$-3 PUFAs. Compositions of PLs vary from one source to another in terms of PLs type or fatty acids nature (short, medium or long chain, saturated or unsaturated), both of them induce different properties and bio functions (Küllenberg et al., 2012). They are important biomolecules that constitute structural building blocks, support cell and organelle membranes, and play a vital role in cell biochemistry and physiology. Additionally, exogenous PLs provided as a dietary source that is characterized by high nutritional value and various beneficial health effects, which are proved by many epidemiological studies (Küllenberg de Gaudry et al., 2014; Zhang, Tao, Wang et al., 2018; Tsoupras et al., 2019). Long-chain $\omega-$ 3 PUFAs, particularly eicosapentaenoic acid, docosapentaenoic acid, and docosahexaenoic acid have drawn public attention as the human body is unable to synthesize these compounds and exert crucial physiological functions (Lee et al., 2017; Saini and Keum, 2018; Haq et al., 2018; Drouin et al., 2019; Haq et al., 2020).

Some health beneficial activities such as anti- 
inflammatory, anti-thrombosis, and anti-oxidative properties of marine PLs were reported (Küllenberg et al., 2012; Burri et al., 2012; Murru et al., 2013; Lordan et al., 2017). Additionally, marine PLs demonstrate superior combination into plasma lipoproteins and cell membranes, including lipoprotein. Marine PLs exhibit strong in vitro and in vivo antithrombotic, antiatherogenic, and cardioprotective properties (Nasopoulou et al., 2010; Nasopoulou et al., 2011; Nasopoulou et al., 2013; Tsoupras, Lordan and Zabetakiset al., 2018). It is currently known that PLs perform pivotal roles to prevent metabolism-related and neurological diseases and to regulate basic biological processes as signalling compounds. Only PS carries a net negative charge, whereas the three rest groups available in the mammalian body such as PC are electrically neutral at physiological $\mathrm{pH}$ with one positive and one negative charge. In recent investigations, marine PLs have shown positive effects in patients with tumor associated weight loss. Approximately one-third $\omega-3$ PUFAs are bound to PLs and two-thirds are bound to triglycerides. Some reports also showed that the uptake and utilization of $\omega-3$ PUFAs bound to PLs were more efficient than those bound to general lipids (Burri et al., 2012).

Many studies have documented that marine PLs not only carry a higher amount of $\omega-3$ PUFAs than normal lipids from the same source but also exhibit better absorption in different tissues (Wijendran et al., 2002; Gbogouri et al., 2006). This might be due to the amphiphilic natures of PLs resulting in better water dispersal ability and higher reactivity with phospholipase than glycerolysis of general lipids. The supplementation of foods with $\omega-3$ PUFAs rich PLs has recently emerged as a food supplement and pharmaceutical application. In this regard, the demands of marine PLs enriched with $\omega$ 3 PUFAs are increasing due to emerging health benefits (Wen et al., 2016; Haq and Chun, 2018; Wang, Wang, $\mathrm{Xu}$ et al., 2018). Therefore, the present review presents a detailed account of different biological and biofunctional roles of marine-derived phospholipids to provide useful references for academia, industrial processor, and consumers as well.

\section{Biological functions of marine PLs}

The review of recent reports on bio-functional properties of $\omega-3$ PUFAs rich marine PLs was summarized as anti-atherosis and cardioprotective, antiinflammatory, neuroprotective, immunological, and liver functions (Figure 1).

\subsection{Anti-atherogenic and cardioprotective functions}

Atherosclerosis disease occurs due to the deposition of fatty tissues inside the arteries' wall, forming an unusual structure known as plaque. Those plaque grow until they burst, rupturing the walls, and clotting blood within the artery. These clots also develop until they block blood flow; and in the case of the coronary artery, this causes a heart attack. This heart disease is the leading cause of mortality worldwide, and platelet is condemned to induce the heart attack and stroke by forming blood clots, and possibly more intriguingly their role as inflammatory cells. In recent years, the oral supplementation of dietary PLs has been investigated widely to reduce blood lipid profiles and cardiovascular problems. Fish roe PLs rich in phosphatidylcholine (PC)

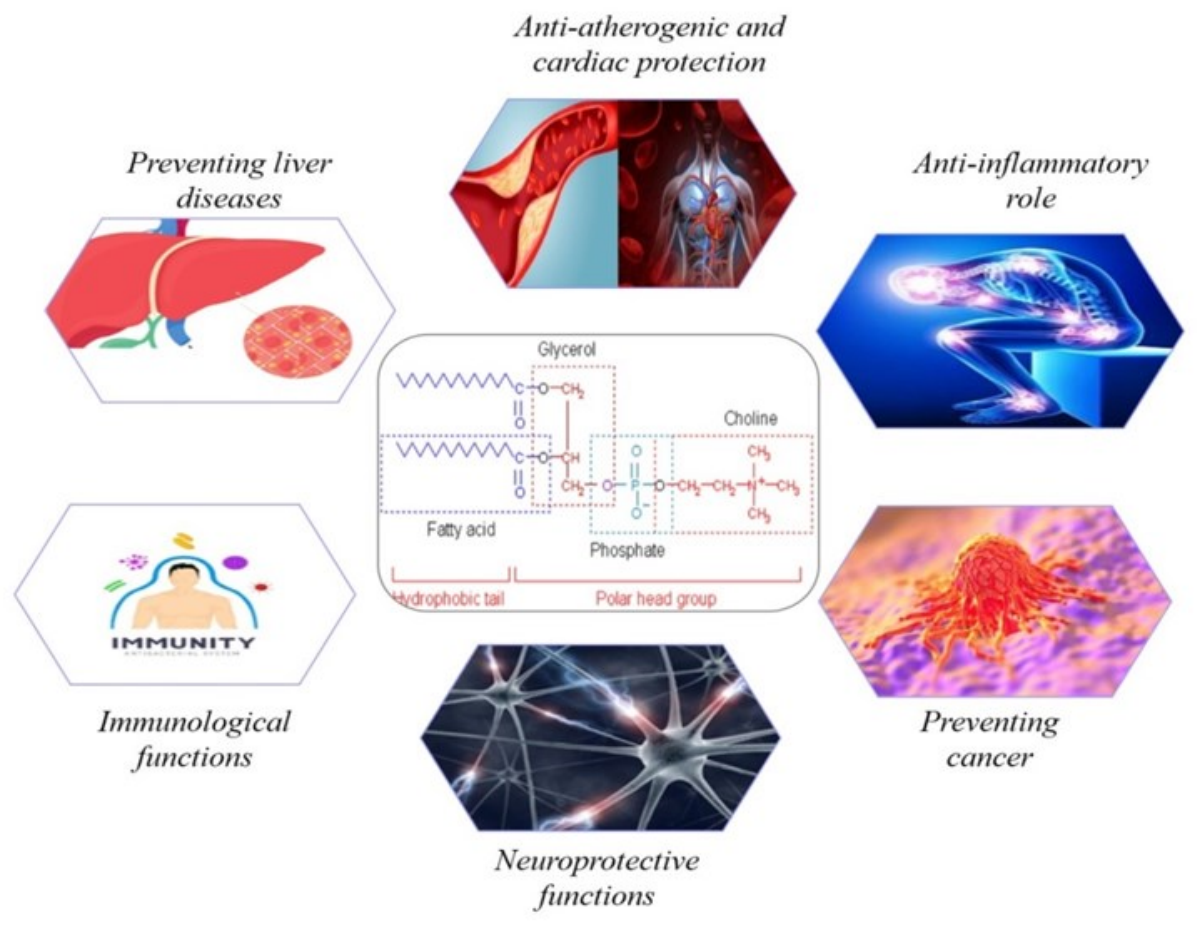

Figure 1. Bio-functional roles of marine phospholipids 
and containing a high amount of $\omega-3$ PUFAs have been shown to reduce blood plasma lipids. PLs not only reduce total cholesterol, LDL cholesterol, and triglycerides but also increase HDL cholesterol. Coronary artery disease and hypercholesterolemic patients are treated with Lovastatin to achieve reduced total cholesterol, LDL levels, and TG but simultaneously displayed to increase platelet activity, which ultimately is a risk factor for coronary heart disease. In this case, application of PLs in patients with cardiovascular disease not only reduces blood cholesterol level but also prevent platelet aggregation. Marine PLs are shown to have remarkable effects on blood lipid reduction in patients suffering from hyperlipidemia (Bunea et al., 2004). Many researchers proved that supplementation of traditional fish oil lowers only blood TG levels, but has no effect on LDL and HDL levels whereas marine PLs reduce LDL, total cholesterol level, and TG level simultaneously increase HDL level. The anti-atherogenic and cardioprotective functions of $\omega-3$ PUFAs studied in recent years are presented in Table 1. Ding et al. (2018) administered EPA and DHA rich PLs to male apolipoprotein E-deficient male mice with a high-fat diet and found a reduction in the atherosclerotic lesion and serum TAG level. PLs from marine organisms was effective in reducing hepatic and serum lipid content and expressing glucose and cholesterol metabolism (Beppu et al., 2017; Runblad et al., 2018). Zhang, Chi, Wu et al. (2018) fed 2\% EPA-PL containing diet to mice for the duration of 4 weeks and reported reduction of not only body TAG level but also hepatic lipogenic genes. They also noticed enhanced hepatic fatty acid $\beta$-oxidation enzyme activity.

\subsection{Anti-inflammatory role}

Inflammation is a necessary biological protective response of the innate immune system to harmful stimuli or physiological triggers such as a pathogen or damaged cells, whereby the tissue is repaired or the pathogenic insult is eliminated. Chronic inflammation is associated with many complications in different diseases, its diagnosis, as well as treatment, creates an enormous challenge for medical practitioners. Additionally, applications of therapeutic treatments up to date were unsuccessful to obtain the desired effect, as a permissive immune environment is a prerequisite for their appropriate activity. It is evident that chronic inflammation and related immunosuppression pose a serious obstacle in the diagnostic and therapeutic area and those develop no chronic inflammation. Immunosuppression poses a serious obstacle in the prognostic and therapeutic areas as they both develop with no tangible clinical signs including unanticipated complications and possible impassiveness to various treatments (Meirow and Baniyash, 2017). Rather than therapeutic interventions, long-standing lifestyles such as maintaining healthy nutrition and exercise may ensure preventive outcomes towards inflammatory expressions. Presently, there is a growing logical rationale for the application of dietary PLs for the treatment of inflammatory problems to control inflammatory reactions. PLs supplementation in chemically induced arthritis rats reduced the level of arthritis most likely due to hindering the neutrophil leukocyte-mediated inflammatory reaction. Marine PLs have demonstrated anti-inflammatory and antithrombotic activities by hindering the platelet-activating factor or plateletactivating factor-receptor related pathways (Lordan et al., 2017; Tsoupras, Lordan and Zabetakis, 2018; Tsoupras et al., 2018). Marine PLs rich in $\omega-3$ PUFAs have demonstrated to decrease inflammatory response by the inhibition of prostaglandins series-2. Krill oil rich in PLs was investigated for its anti-inflammatory activities in patients with rheumatoid arthritis and elevated Creactive protein (CRP). The CRP levels and arthritic symptoms such as joint pains, stiffness, and functional impairment were reduced significantly (Table 2). Eicosanoids and PAF are mostly known lipid proinflammatory mediators responsible for inflammatory responses that are promisingly targeted by dietary interventions, especially to those food containing bioactive PLs (Burri et al., 2012; Zabetakis, 2013). There is another therapeutic application of marine PLs is the treatment of the premenstrual syndrome. It is supposed that menstrual pain and cramps are caused by $\omega-6$ fatty acids mediated inflammation, whereas supplementation of the $\omega-3$ fatty acids could alleviate the mentioned symptoms. Krill oil rich in PLs was revealed to reduce not only abdominal pain, swelling, and joint pain but also improve emotional symptoms since brain PLs rich in docosahexaenoic acids are involved in brain functions. Marine PLs modulate neurotransmitters and thereby, positively affect the psychological and emotional symptoms in premenstrual women (Küllenberg et al., 2012). Menstrual pain and cramps in women are caused by omega- 6 fatty acids mediated inflammation and the supplementation of PUFAs rich PLs could alleviate the above-mentioned problems.

\subsection{Marine PLs in preventing cancer}

Cancer is an assemblage of diseases involved with abnormal cell growth with the capability to invade or spread to other parts of the body. Cancer cell membranes derive some unusual properties, for example changing the ability to adhesive characteristics that are observed in normal cells. This enables cancer cells to migrate from their surrounding tissue to other tissues or organs, causing tumour metastases. For example, the membranes 


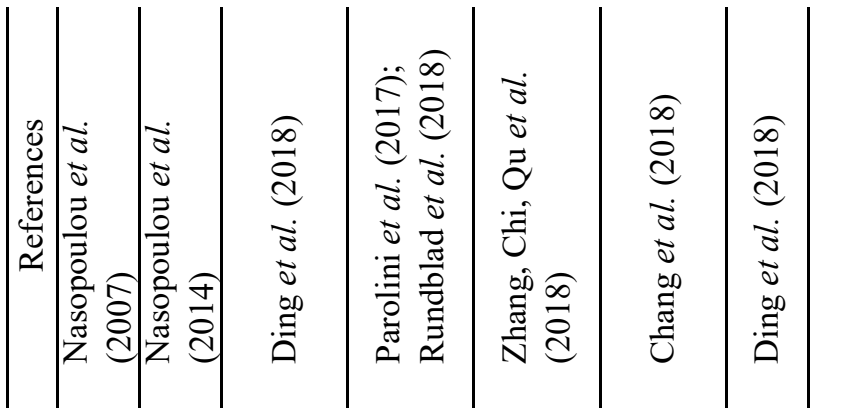

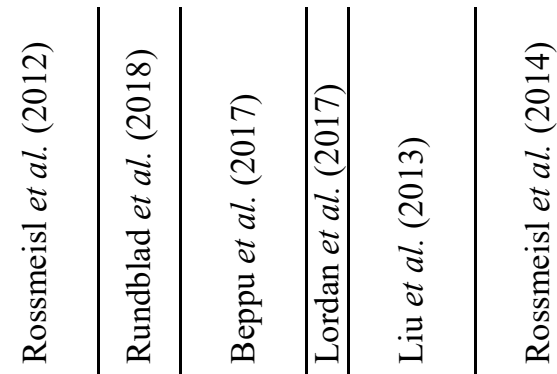

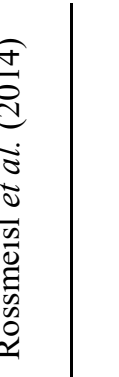

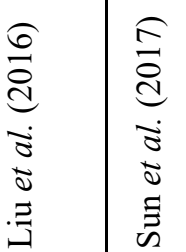

e

这

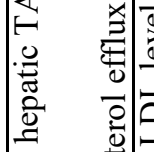

فํ.

桭

$\sqrt[5]{0.0}$

:

$\frac{7}{\exists}$ 它

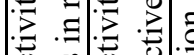

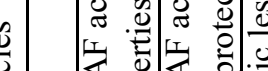

品 空

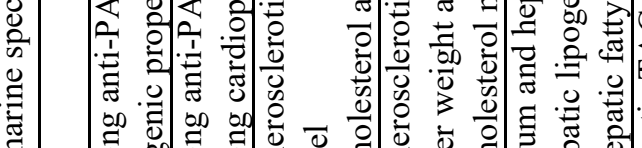

氙节

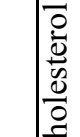

ฮี

苞

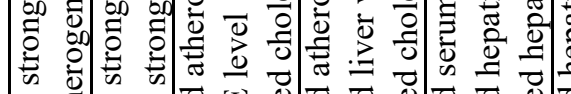

:⿹气

苛苛

可

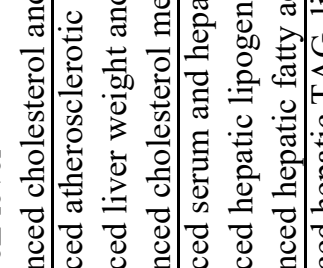

駦

号

:

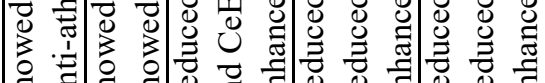
旅

离

:

:

泀

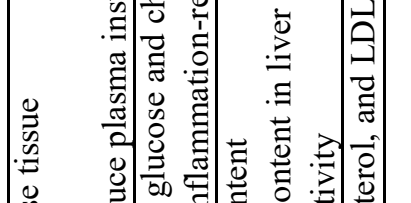

恿

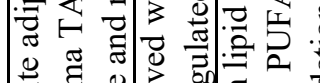

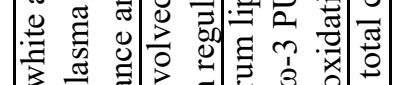

势

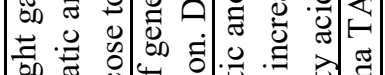

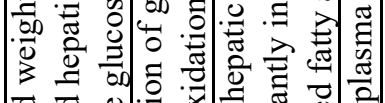

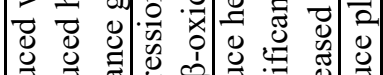

焉

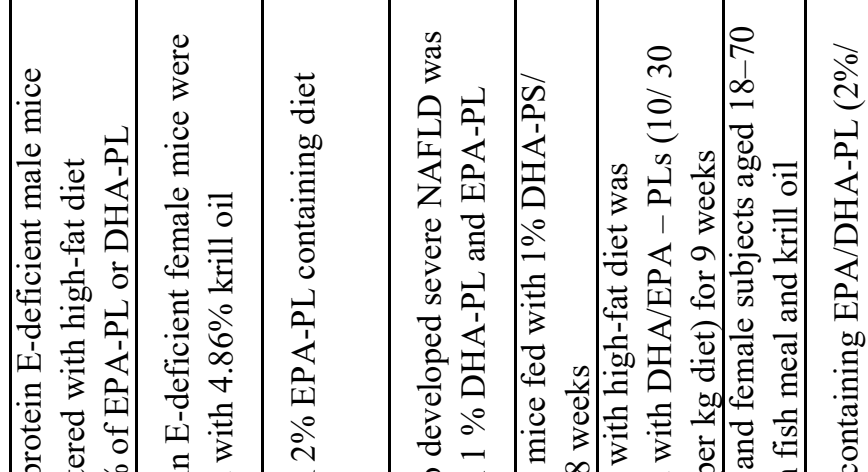

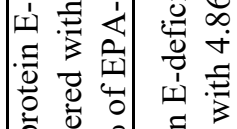

产 离

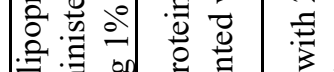

उ $\frac{2}{0}$

娄

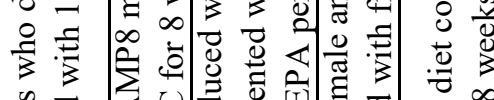

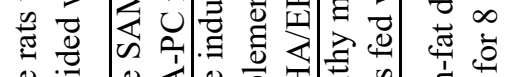

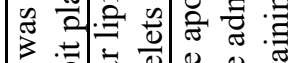

을

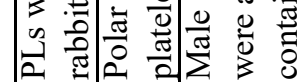

安 㝕
छ

兽它

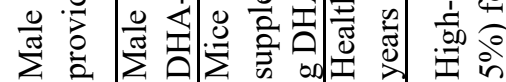

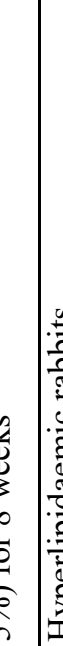

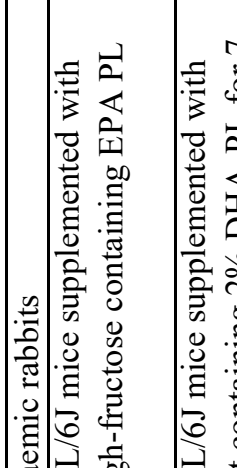

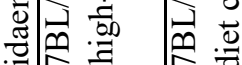

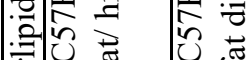

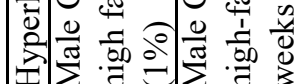

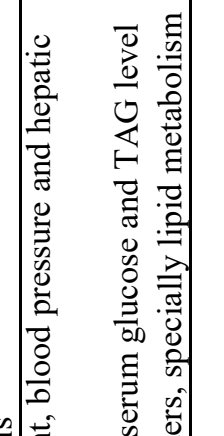
0 일 $\because$ के

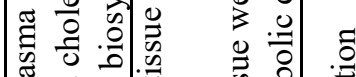

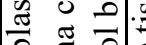

a

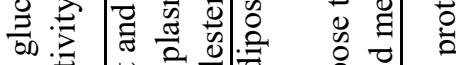

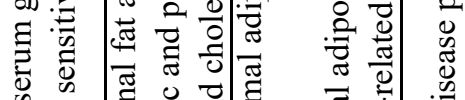

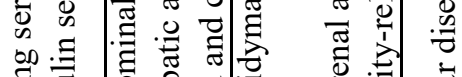
言至

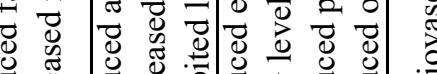
芯

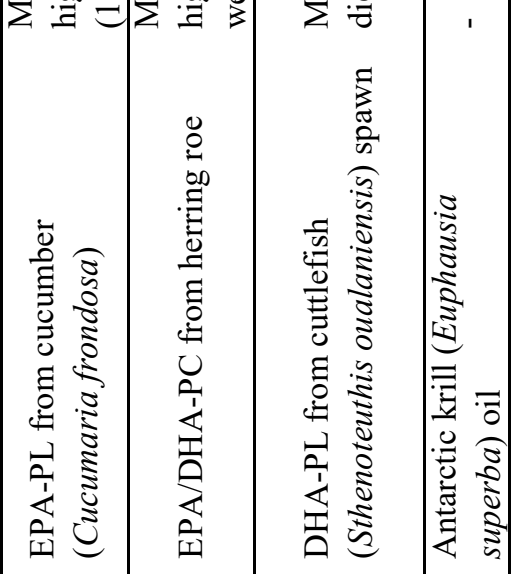


of prostate and breast cancer cells were shown to have a higher concentration of lipid-containing cholesterol which is associated with higher apoptotic sensitivity. Regulation and alternation of the composition of lipid rafts can potentially alter cancer cell viability and metastatic behaviour (Table 3). Many studies have described the beneficial effects of PLs in cancer and metastasis inhibition (Zhang et al., 2019). Sakakima et al. (2007) conducted an in vitro study with hepatic cancer cell lines and reported that PLs and menaquinone4 restrained the growth of cancer cells in a dosedependent manner. Supplementation with PC and menaquinone-4 in rats showed a distinct suppression of nodule formation and pre-neoplastic liver lesions in tested rats. Administering PC with menaquinone-4 showed more significant effects on the reduction of cancer cells due to synergistic effects. Marine PLs extracted from starfish and squid meal containing $\omega-3$ PUFAs were observed to prevent the growth of chemically induced colon cancer in rats which was explained by an enhanced lipid peroxidation as a consequence of structural and functional shifts in the cellular membrane. Additionally, to prove the preventive effects of colon cancer in a mouse model, sphingomyelin was administered and drastic preventive effects on colon cancer formation. A high intake of marine PLs rich in $\omega$ 3 PUFAs recovered from fish has shown to reduce the metastatic progression of prostate cancer (Küllenberg de Gaudry et al., 2014). Marine PLs rich in $\omega-3$ PUFAs supplemented in patients who suffered from severe weight reduction due to pancreatic cancer aided in weight stabilization and improved life span (Werner et al., 2017).

\subsection{Neuroprotective functions}

Neurological diseases primarily affect the structure or functions of neurons in the human brain. Neurons are the building blocks of the nervous system which include the brain and spinal cord. Many neurological diseases include Alzheimer's disease, Parkinson's disease, Amyotrophic lateral sclerosis, Huntington's disease, Motor neuron disease, etc. These diseases are incurable, resulting in gradual degeneration and/or death of neuron cells. The lipid composition of brain cells changes with ageing; more clearly, the amount of $\omega-3$ PUFAs in the brain cell tends to reduce with age, resulting in membrane fluidity reduction and cholinergic activities via retarded $\mathrm{Na}+-$ and $\mathrm{Ca}+-$ channels in the membrane are reduced. In these circumstances, they require PC and PUFAs for their excitability and neurotransmitter release (Table 4). It can be assumed that memory decline and the diminished learning capacity found in elderly people are consequences of a decrease of PC and/or PUFAs in the brain tissue. Marine PLs are a potential and effective carrier of essential $\omega-3$ PUFAs such as DHA to the brain. Some researchers have proven that the preferential incorporation of DHA bound to PC into young rat brain (Table 4). Oral supplementation of marine PLs may play an important role not only in the elderly but also during pregnancy and infancy for neurological development. Supplementation of PLs rich in DHA may improve learning capability and visual function in age-related impairment and $\omega-3$ PUFAs deficiency.

\subsection{Immunological functions}

PLs include a large group of lipids in cells and organelles which form membrane structures. In conjunction with their metabolic products, they control a range of aspects of innate immune cell biology including aggregation, shape change, blood clotting, and degranulation. The plasma membrane lipids such as glycerophospholipids, sterols, and sphingolipids play essential roles in regulating $\mathrm{T}$ cell (a cell system plays a key role in the immune response) differentiating, signalling, and effector functions. PLs hydrolysis provides a substrate for cell-cell communication; enable regulations of immunity, hemostasis, thrombosis, and vascular inflammation (O'Donnell et al., 2018). PLs are also recognized by $\mathrm{T}$ cells, which are essential for the recognition of infection or cancer, as well as antigens. PLs, sphingomyelin and cholesterol are enriched at the contact zone between $\mathrm{T}$ cells and antigen-presenting cells during peptide/ major histocompatibility complexes recognition where a platform of lipid domains is necessary for optimal $\mathrm{T}$ cell signalling (Tuosto and $\mathrm{Xu}$, 2018). The cholesterol and PL ratio in the cell membrane increases with age which has consequences in their functions and properties. For example, an increase in the cholesterol and PL ratio in lymphocytes reduces their immunological functions (Küllenberg et al., 2012). The membrane viscosity of lymphocytes can be modified by altering optimal cholesterol and PL ratio, therefore, it is anticipated that an increase in PL concentration in lymphocyte cell membrane could regain the immunological function in elderly people. This effect was not found in the lymphocyte of young mice, supporting the theory those external PLs restores the optimal cholesterol and PL ratio in the affected lymphocyte membrane and all other cells, too maintaining their usual cell functions. The number of lymphocytes and macrophage phagocytic capacity was significantly improved with PLs supplementation indicating a modulatory positive effect of PLs on the immune function. PLs showed significant improvement of polymorphonuclear leukocyte phagocytic and killing activity and an increase in amino acid release in individuals feed with PLs. The amino acid release indicated the capability to change the membrane 


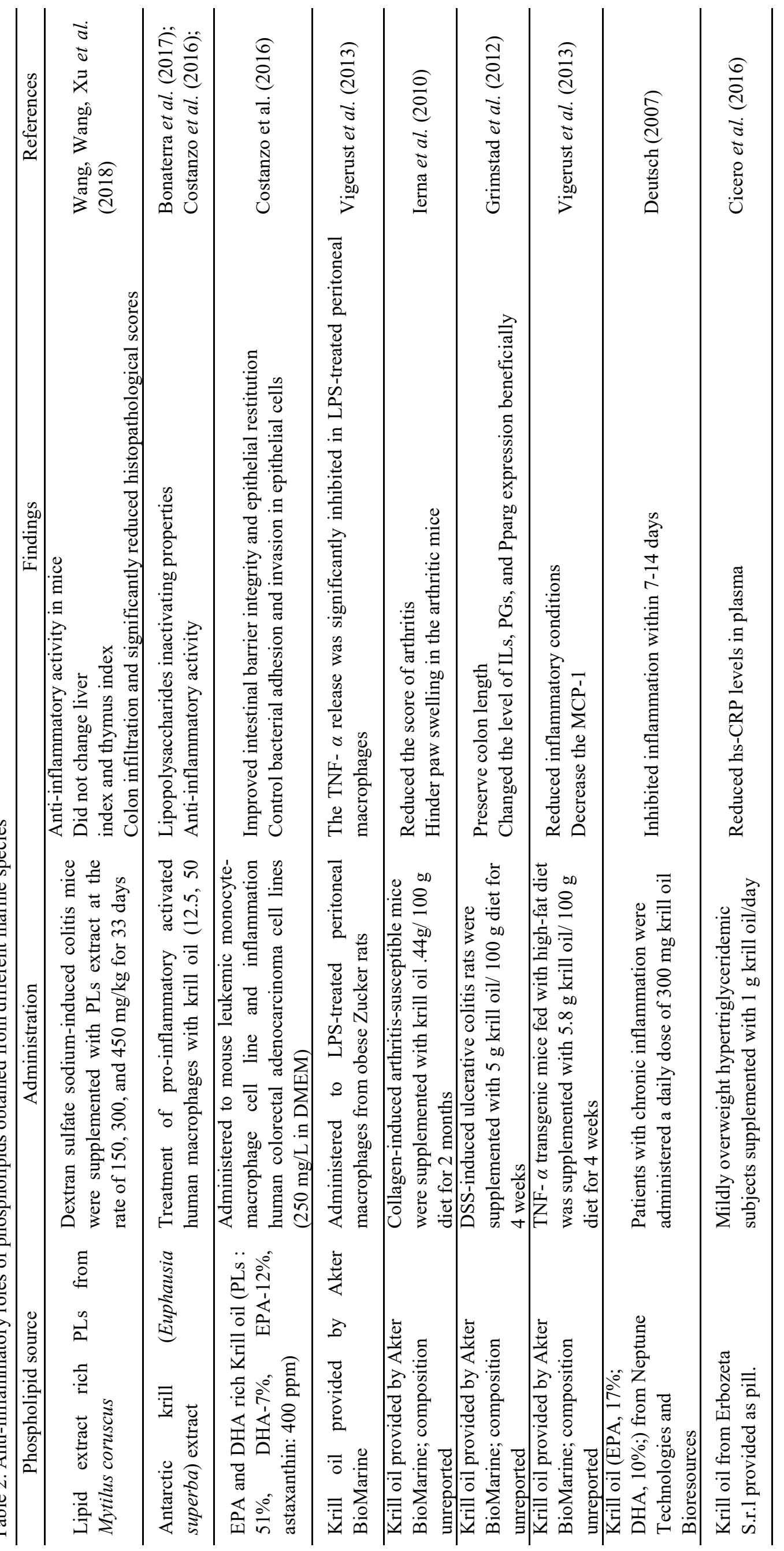


Haq and Suraiya / Food Research 5 (5) (2021) 1 - 16

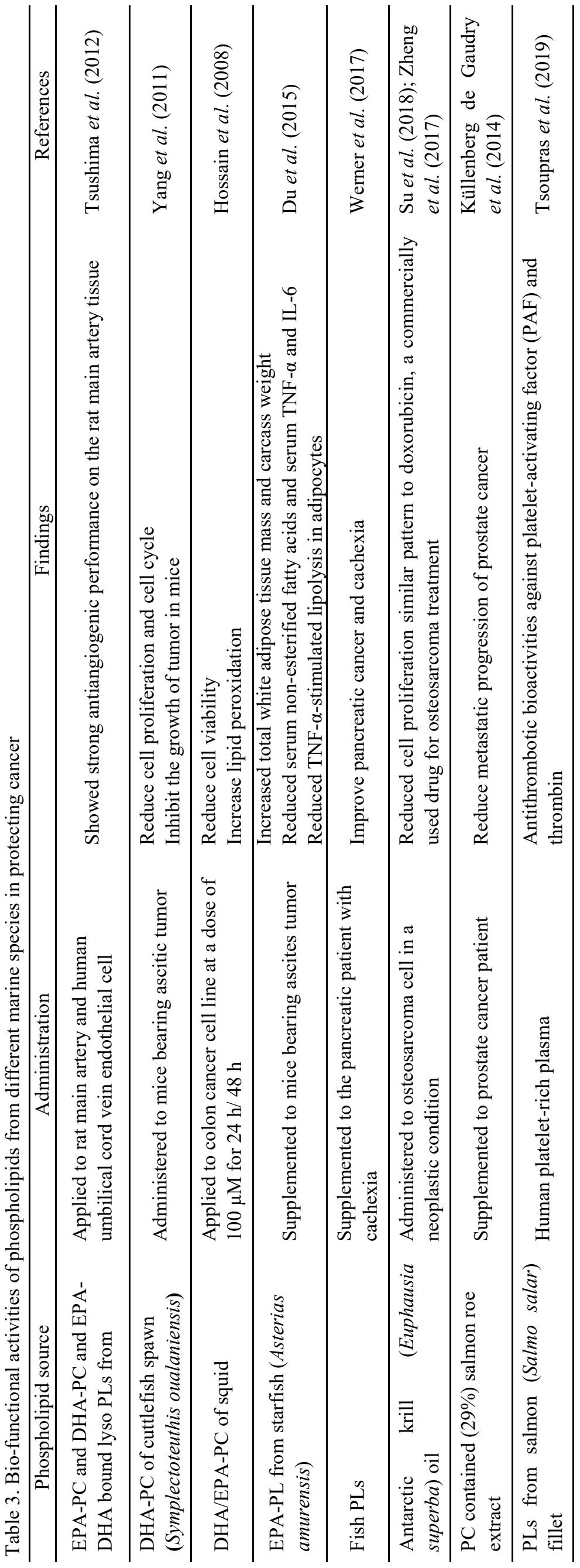




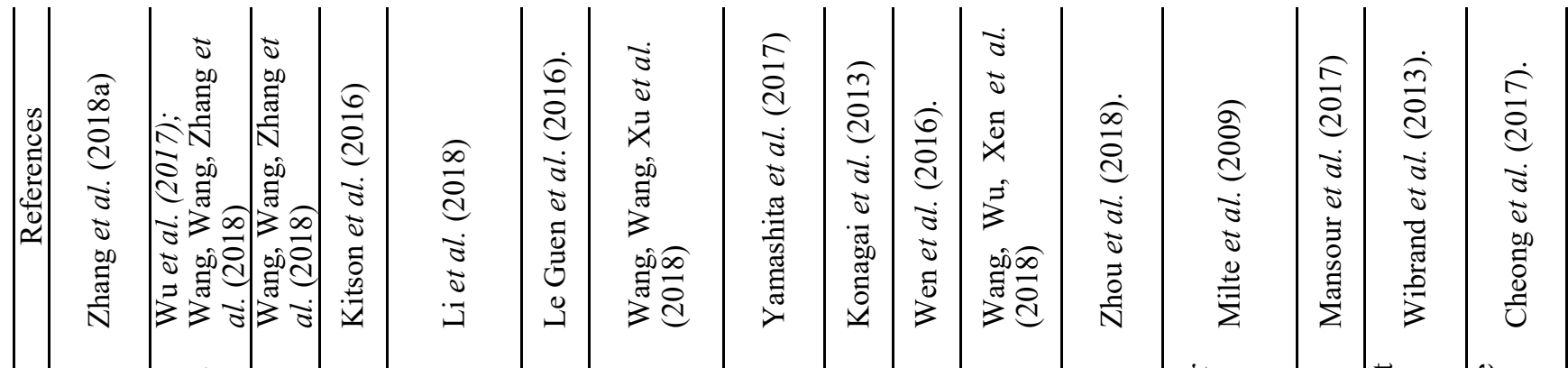

.

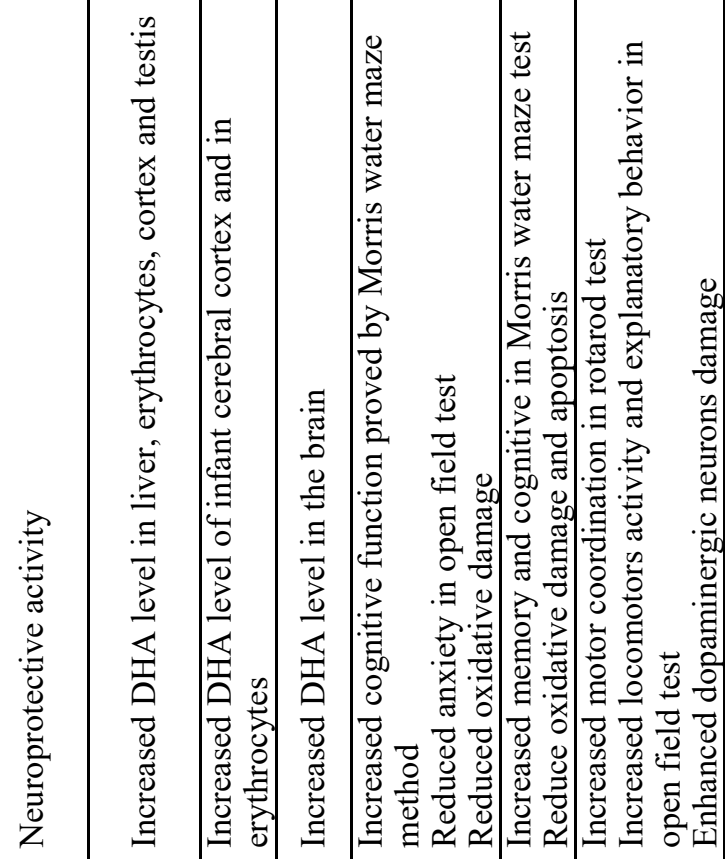
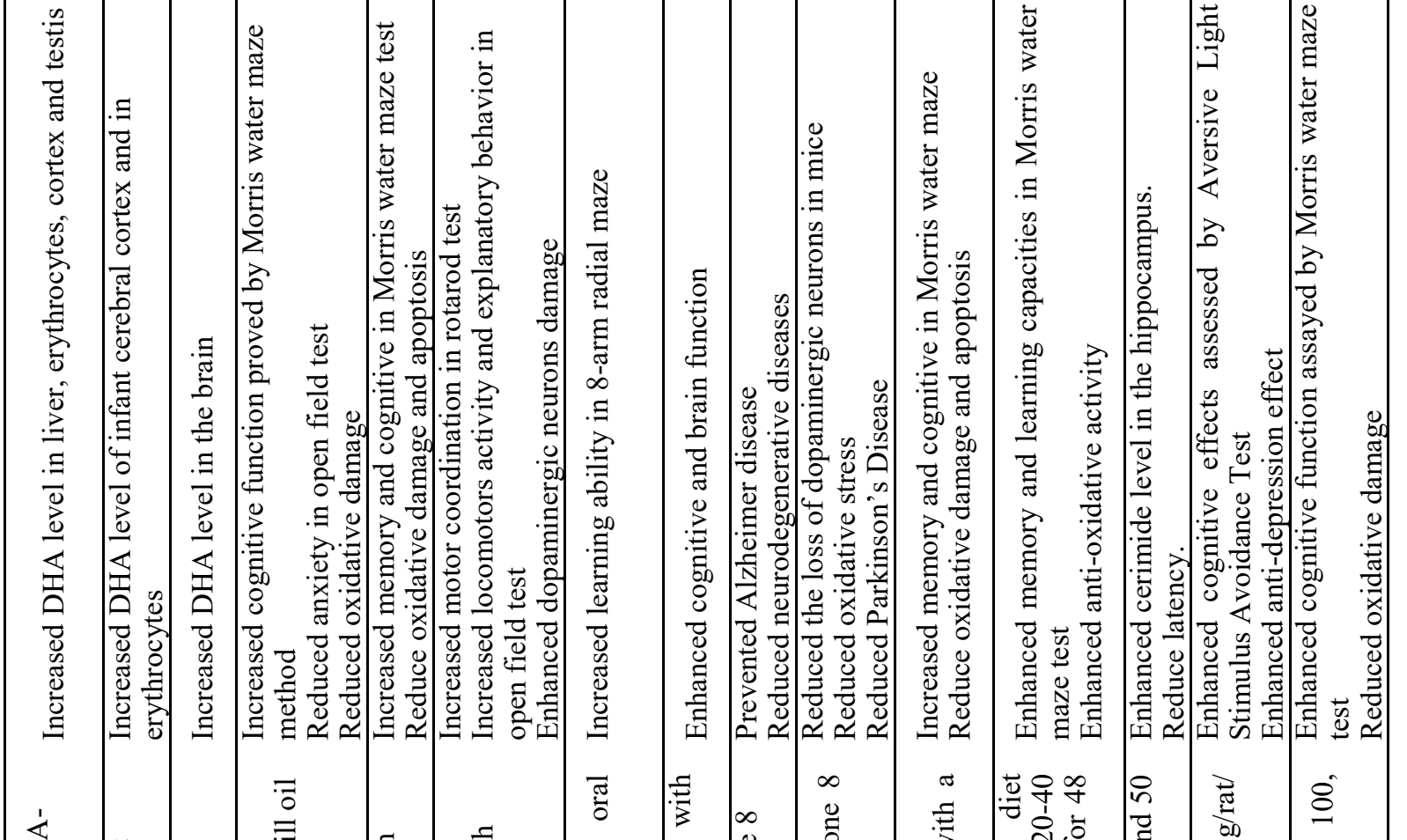

西

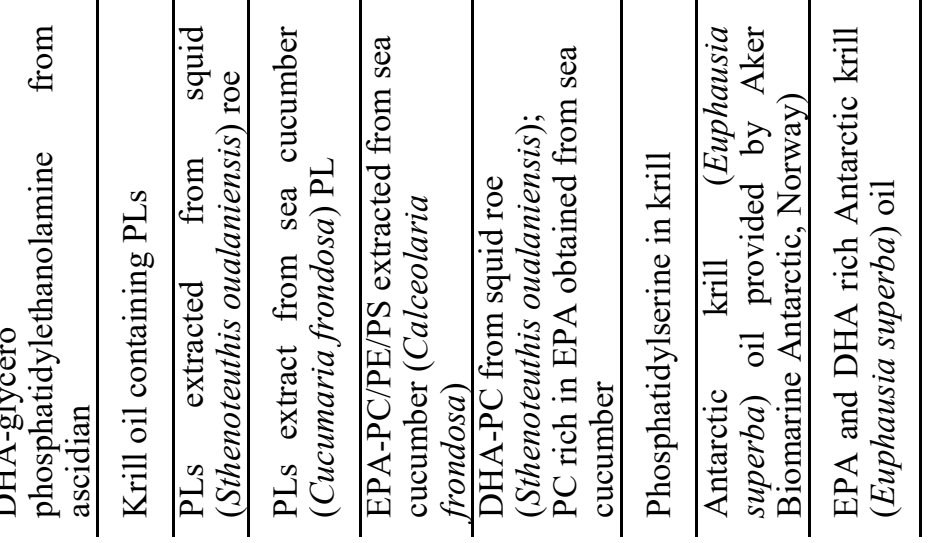




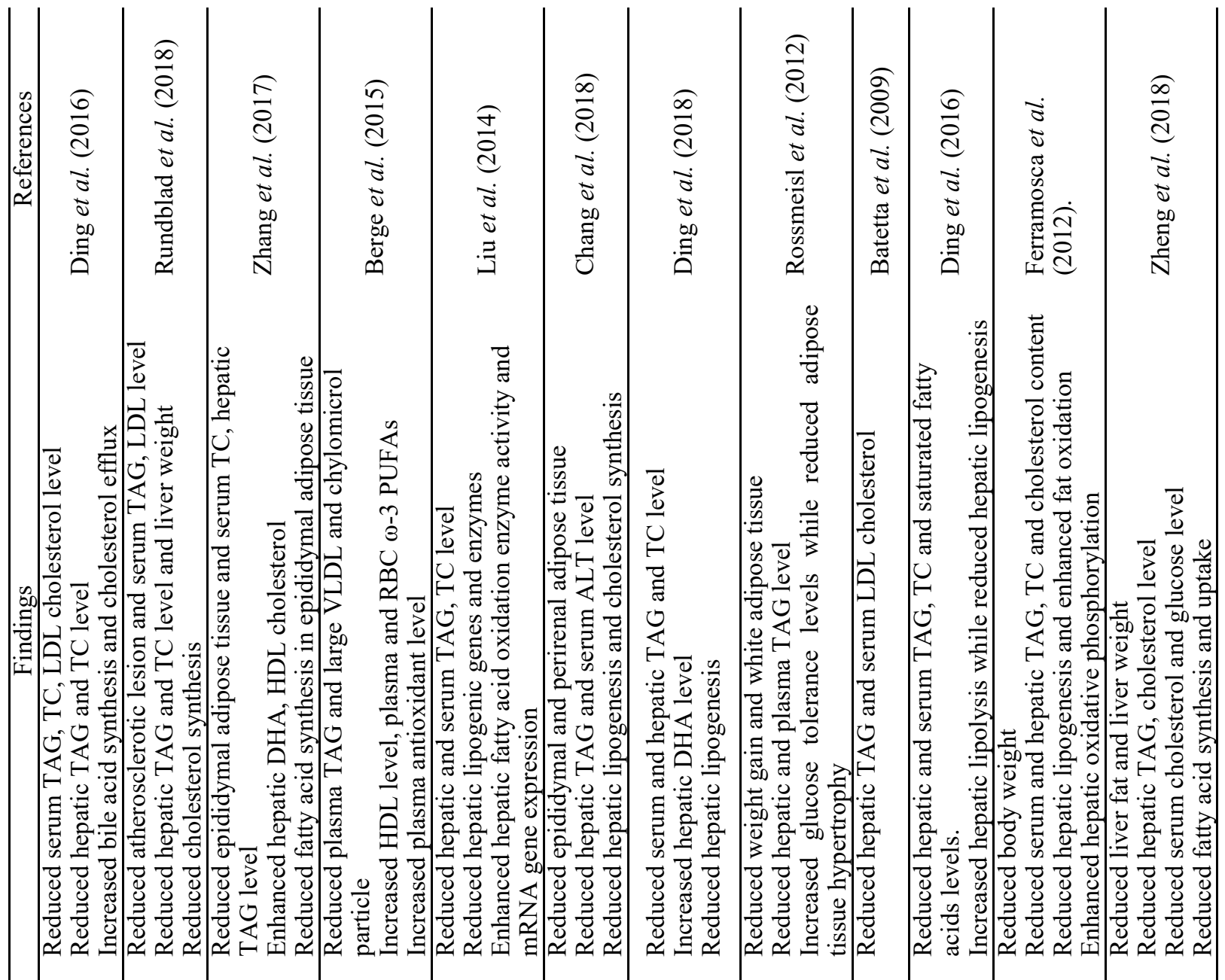

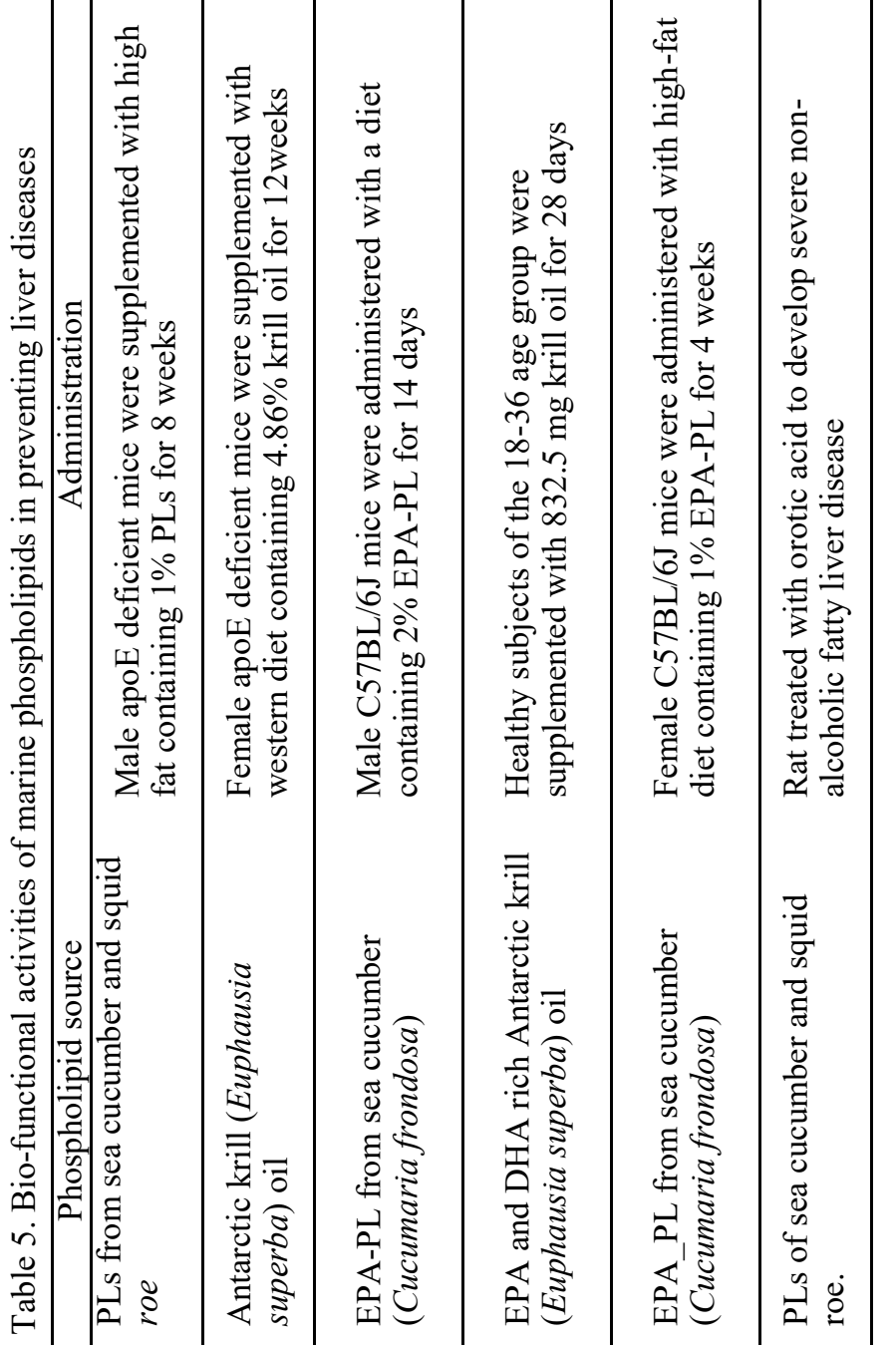

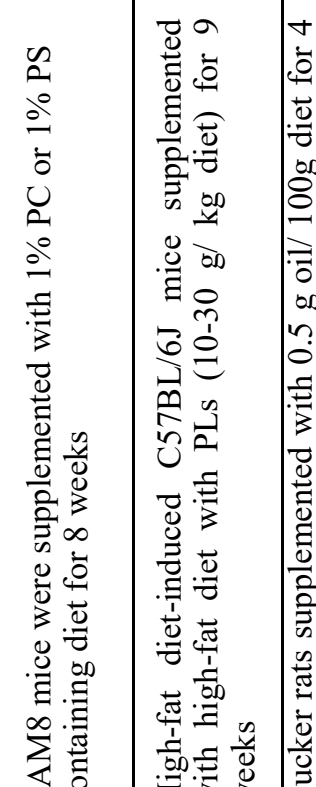

总

กิ

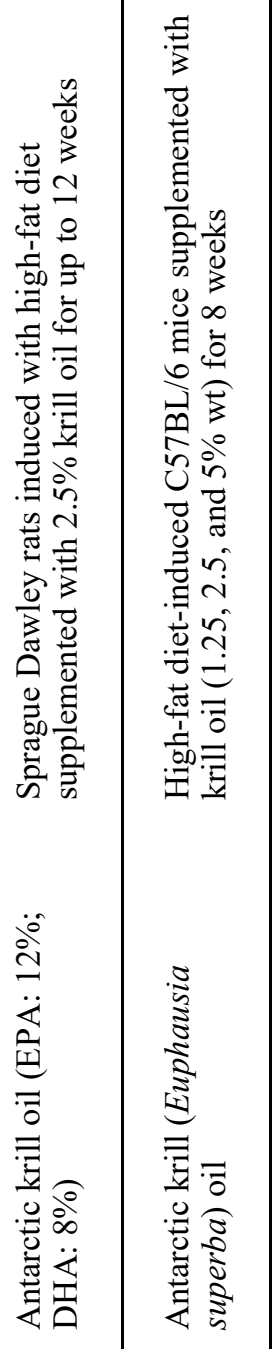




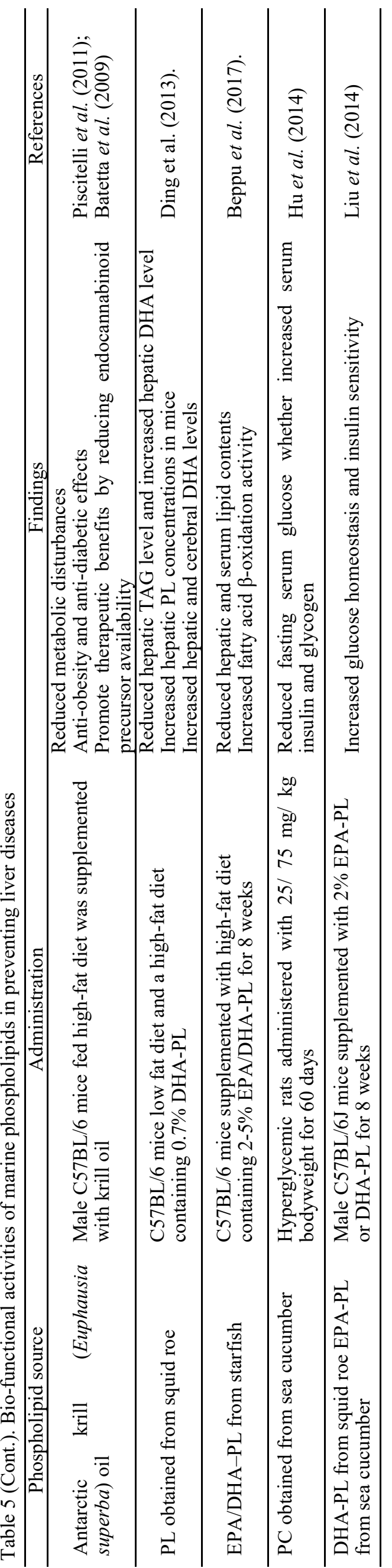


composition of polymorphonuclear leukocytes, resulting in an improvement of immunological properties.

\subsection{Preventing liver diseases}

Fatty liver disease is a health problem caused by obesity, alcohol drinking, sedentary lifestyle, and diabetes mellitus for which an established treatment is not yet available. Intake of PLs has been widely recommended for the treatment of liver disorders including fatty liver problems and viral hepatitis. A recent review showed that the application of PLs was indeed beneficial for hepatic disorders (Gundermann et al., 2011). Due to excess alcohol consumption, the membrane PLs level of hepatic cells is reduced or altered which ultimately affects the membrane fluidity that leads to damaged membrane associated with enzyme carrier and receptor activities. Under prolonged conditions, these can lead to a change in collagen metabolism resulting in the formation of fibrosis and cirrhosis. Moreover, the liver is a vital organ for lipid metabolism. Due to dyslipidemia, various pathomechanisms such as lipid peroxidation, modification of lipoprotein structure, reduction in lipase enzyme, and lipid functions interact which trigger an increase in serum cholesterol and triglyceride levels. This ultimately results in a low level of high-density lipoprotein (HDL) secretion into the blood system that leads to reduced take-up and transportation of cholesterol from the periphery to the liver for metabolism (Gundermann et al., 2011). Supplementation of PLs directly incorporated into the PLs deficient hepatic cells, which normalize the activity of membrane-bound enzymes and reduce alcoholinduced liver injury. The mechanisms were discussed as the ability of PLs' to prevent acetaldehyde mediated hepatic collagen accumulation by stimulating collagenase enzyme activity. In a human trial, this effect was investigated in a placebo-controlled randomized clinical trial continued for around 20 years, showing that PLs improved liver problems in drinkers. Moreover, the hepatocyte apoptosis, as well as the formation of TNF-a by Kupper cells and lipid peroxidation, was reduced (Table 5). The PLs supplementation was prevented not only the development of alcohol-induced liver cirrhosis but also early liver changes induced by excess alcohol consumption (e.g. hyperlipidemia and fatty liver). Actually, alcohol intake enhances plasma lipids, which is transported to and deposited in the liver as TG and cholesterol ester form which causes alcohol-induced liver damage. The mechanisms of liver lipid deposition prevention by PLs were explained that PLs reactivate the alcohol-induced inhibition of mitochondrial fatty acid oxidation and thus reduced liver damage.

All the hepatic protective activities were attributed to the PLs since the functionalities were not found during supplementing TG or head group alone. PLs provided much better results in reducing liver TG levels in rats compared to a TG supplementation with almost similar fatty acids composition. Patients with chronic alcoholinduced liver damage treated with PC were shown to be effective in improving liver-related symptoms such as cholestasis and icterus. Moreover, PLs supplementation was shown to be effective not only in alcohol-related liver disease but also in hepatic damage caused by viral infections or toxins. Improvement of liver functions was reported with PLs supplementation to patients suffering from non-alcoholic liver damage (Varganova et al., 2019). The primary site for PLs synthesis and metabolism is hepatic tissue. The fatty acids profile of liver PLs and TG is known to be influenced by several factors including dietary intake, endogenous metabolism, gender, and age. FAs are important in maintaining the modulation of membrane fluidity, interacting intracellular signalling pathways, and performing as a substrate for the production of signalling molecules.

\section{Conclusion}

Significant progress has been made on the studies of bio-functional roles of $\omega-3$ PUFAs rich marine PLs. A considerable extent of suggestion indicated that $\omega-3$ PUFAs rich marine PLs are more beneficial for health aspects compared to $\omega-3$ PUFAs in TAG/ EE forms, and even from terrestrial PLs. An important source of marine PLs might be fish by-products, which can reduce the competition to use terrestrial resources for the extractions and utilization of PLs. Thus, the full health advantages of $\omega$-3 PUFAs rich marine PLs could be maximized in our daily applications.

\section{Conflicts of interest}

The authors declare no conflicts of interest.

\section{References}

Batetta, B., Griinari, M., Carta, G., Murru, E., Ligresti, A., Cordeddu, L., Giordano, E., Sanna, F., Bisogno, T., Uda, S. and Collu, M. (2009). Endocannabinoids may mediate the ability of (n-3) fatty acids to reduce ectopic fat and inflammatory mediators in obese Zucker rats. The Journal of Nutrition, 139(8), 14951501. https://doi.org/10.3945/jn.109.104844

Beppu, F., Li, H., Yoshinaga, K., Nagai, T., Yoshinda, A., Kubo, A., Kanda, J. and Gotoh, N. (2017). Dietary starfish oil prevents hepatic steatosis and hyperlipidemia in C57BL/6N mice fed high-fat diet. Journal of Oleo Science, 66(7), 761-769. https://doi.org/10.5650/jos.ess 17038 
Berge, R.K., Ramsvik, M.S., Bohov, P., Svardal, A., Nordrehaug, J.E., Rostrup, E., Bruheim, I. and Bjørndal, B. (2015). Krill oil reduces plasma triacylglycerol level and improves related lipoprotein particle concentration, fatty acid composition and redox status in healthy young adults-a pilot study. Lipids in Health and Disease, 14(1), 163. https://doi.org/10.1186/s12944-015-0162-7

Bonaterra, G.A., Driscoll, D., Schwarzbach, H. and Kinscherf, R. (2017). Krill oil-in-water emulsion protects against lipopolysaccharide-induced proinflammatory activation of macrophages in vitro. Marine Drugs, 15(3), 74. https:// doi.org/10.3390/md15030074

Burri, L., Hoem, N., Banni, S. and Berge, K. (2012). Marine omega-3 phospholipids: Metabolism and biological activities, International Journal of Molecular Science, 13(11), 15401-15419. https:// doi.org/10.3390/ijms131115401

Chang, M., Zhang, T., Han, X., Tang, Q., Yanagita, T., Xu, J., Xue, C. and Wang, Y. (2018). Comparative analysis of EPA/DHA-PL forage and liposomes in orotic acid-induced nonalcoholic fatty liver rats and their related mechanisms. Journal of Agricultural and Food Chemistry, 66(6), 1408-1418. https:// doi.org/10.1021/acs.jafc.7b05173

Cheong, L.Z., Sun, T., Li, Y., Zhou, J., Lu, C., Li, Y., Huang, Z. and Su, X. (2017). Dietary krill oil enhances neurocognitive functions and modulates proteomic changes in brain tissues of d-galactose induced aging mice. Food and Function, 8(5), 20382045. https://doi.org/10.1039/C6FO01848C

Cicero, A.F., Rosticci, M., Morbini, M., Cagnati, M., Grandi, E., Parini, A. and Borghi, C. (2016). Lipidlowering and anti-inflammatory effects of omega 3 ethyl esters and krill oil: a randomized, cross-over, clinical trial. Archives of Medical Science, 12(3), 507. https://doi.org/10.5114/aoms.2016.59923

Costanzo, M., Cesi, V., Prete, E., Negroni, A., Palone, F., Cucchiara, S., Oliva, S., Leter, B. and Stronati, L. (2016). Krill oil reduces intestinal inflammation by improving epithelial integrity and impairing adherent -invasive Escherichia coli pathogenicity. Digestive and Liver Disease, 48(1), 34-42. https:// doi.org/10.1016/j.dld.2015.09.012

Deutsch, L. (2007). Evaluation of the effect of Neptune Krill Oil on chronic inflammation and arthritic symptoms. Journal of the American College of Nutrition, 26(1), 39-48. https:// doi.org/10.1080/07315724.2007.10719584

Ding, L., Wang, D., Zhou, M., Du, L., Xu, J., Xue, C. and Wang, Y. (2016). Comparative study of EPAenriched phosphatidylcholine and EPA-enriched phosphatidylserine on lipid metabolism in mice. Journal of Oleo Science, 65(7), 593-602. https://doi.org/10.5650/jos.ess 16005

Ding, L., Zhang, T., Che, H., Zhang, L., Xue, C., Chang, Y. and Wang, Y. (2018). DHA-enriched phosphatidylcholine and DHA-enriched phosphatidylserine improve age-related lipid metabolic disorder through different metabolism in the senescence-accelerated mouse. European Journal of Lipid Science and Technology, 120(6), 1700490. https://doi.org/10.1002/ejlt.201700490

Ding, N., Xue, Y., Tang, X., Sun, Z.M., Yanagita, T., Xue, C.H. and Wang, Y.M. (2013). Short-term effects of different fish oil formulations on tissue absorption of docosahexaenoic acid in mice fed high -and low-fat diets. Journal of Oleo Science, 62(11), 883-891. https://doi.org/10.5650/jos.62.883

Drouin, G., Catheline, D., Guillocheau, E., Gueret, P., Baudry, C., Le Ruyet, P., Rioux, V. and Legrand, P. (2019). Comparative effects of dietary n-3 docosapentaenoic acid (DPA), DHA and EPA on plasma lipid parameters, oxidative status and fatty acid tissue composition. The Journal of Nutritional Biochemistry, 63, 186-196. https://doi.org/10.1016/ j.jnutbio.2018.09.029

Du, L., Yang, Y.H., Wang, Y.M., Xue, C.H., Kurihara, H. and Takahashi, K. (2015). EPA-enriched phospholipids ameliorate cancer-associated cachexia mainly via inhibiting lipolysis. Food and Function, 6 (12), 3652-3662. https://doi.org/10.1039/ C5FO00478K

Ferramosca, A., Conte, A., Burri, L., Berge, K., De Nuccio, F., Giudetti, A.M. and Zara, V. (2012). A krill oil supplemented diet suppresses hepatic steatosis in high-fat fed rats. PloS One, 7(6), e38797. https://doi.org/10.1371/journal.pone.0038797

Gbogouri, G.A., Linder, M., Fanni, J. and Parmentier, M. (2006). Analysis of lipids extracted from salmon (Salmo salar) heads by commercial proteolytic enzymes. European Journal of Lipid Science and Technology, 108(9), 766-775. https:// doi.org/10.1002/ejlt.200600081

Grimstad, T., Bjørndal, B., Cacabelos, D., Aasprong, O.G., Janssen, E.A., Omdal, R., Svardal, A., Hausken, T., Bohov, P., Portero-Otin, M. and Pamplona, R. (2012). Dietary supplementation of krill oil attenuates inflammation and oxidative stress in experimental ulcerative colitis in rats. Scandinavian Journal of Gastroenterology, 47 (1), 49-58. https:// doi.org/10.3109/00365521.2011.634025

Gundermann, K.J., Kuenker, A., Kuntz, E. and Droździk, M. (2011). Activity of essential phospholipids (EPL) 
from soybean in liver diseases. Pharmacological Reports, 63(3), 643-659. https://doi.org/10.1016/ S1734-1140(11)70576-X

Haq, M., Park, S.K., Kim, M.J., Cho, Y.J. and Chun, B.S. (2018). Modifications of Atlantic salmon byproduct oil for obtaining different $\omega-3$ polyunsaturated fatty acids concentrates: An approach to comparative analysis. Journal of Food and Drug Analysis, 26(2), 545-556. https:// doi.org/10.1016/j.jfda.2017.05.006

Haq, M., Pendleton, P. and Chun, B.S. (2020). Utilization of Atlantic salmon by-product oil for omega-3 fatty acids rich 2-monoacylglycerol production: Optimization of enzymatic reaction parameters. Waste and Biomass Valorization, 11(1), 153-163. https://doi.org/10.1007/s12649-018-0392-9

Hossain, Z., Hosokawa, M. and Takahashi, K. (2008). Growth inhibition and induction of apoptosis of colon cancer cell lines by applying marine phospholipid. Nutrition and Cancer, 61(1), 123-130. https://doi.org/10.1080/01635580802395725

Hu, S., Xu, L., Shi, D., Wang, J., Wang, Y., Lou, Q. and Xue, C. (2014). Eicosapentaenoic acid-enriched phosphatidylcholine isolated from Cucumaria frondosa exhibits anti-hyperglycemic effects via activating phosphoinositide 3-kinase/protein kinase B signal pathway. Journal of Bioscience and Bioengineering, 117(4), 457-463. https:// doi.org/10.1016/j.jbiosc.2013.09.005

Ierna, M., Kerr, A., Scales, H., Berge, K. and Griinari, M. (2010). Supplementation of diet with krill oil protects against experimental rheumatoid arthritis. BMC Musculoskeletal Disorders, 11(1), 136. https://doi.org/10.1186/1471-2474-11-136

Kitson, A.P., Metherel, A.H., Chen, C.T., Domenichiello, A.F., Trepanier, M.O., Berger, A. and Bazinet, R.P. (2016). Effect of dietary docosahexaenoic acid (DHA) in phospholipids or triglycerides on brain DHA uptake and accretion. The Journal of Nutritional Biochemistry, 33, 91-102. https://doi.org/10.1016/ j.jnutbio.2016.02.009

Konagai, C., Yanagimoto, K., Hayamizu, K., Han, L., Tsuji, T. and Koga, Y. (2013). Effects of krill oil containing n-3 polyunsaturated fatty acids in phospholipid form on human brain function: a randomized controlled trial in healthy elderly volunteers. Clinical Interventions in Aging, 8, 12471257. https://doi.org/10.2147/CIA.S50349

Küllenberg de Gaudry, D., Taylor, L.A., Kluth, J., Hübschle, T., Fritzsche, J., Hildenbrand, B., Pletschen, L., Schilli, K., Hodina, A., Griffith, L.S. and Breul, J. (2014). Effects of marine phospholipids extract on the lipid levels of metastatic and nonmetastatic prostate cancer patients. International Scholarly Research Notices, 2014, 249204. https:// doi.org/10.1155/2014/249204

Küllenberg, D., Taylor, L.A., Schneider, M. and Massing, U. (2012). Health effects of dietary phospholipids. Lipids in Health and Disease, 11(1), 3-19. https://doi.org/10.1186/1476-511X-11-3

Le Guen, M., Chaté, V., Hininger-Favier, I., Laillet, B., Morio, B., Pieroni, G., Schlattner, U., Pison, C. and Dubouchaud, H. (2016). A 9-wk docosahexaenoic acid-enriched supplementation improves endurance exercise capacity and skeletal muscle mitochondrial function in adult rats. American Journal of Physiology-Endocrinology and Metabolism, 310(3), 213-224. https://doi.org/10.1152/ ajpendo.00468.2014

Lee, H.J., Haq, M., Saravana, P.S., Cho, Y.N. and Chun, B.S. (2017). Omega-3 fatty acids concentrate production by enzyme-catalyzed ethanolysis of supercritical $\mathrm{CO}_{2}$ extracted oyster oil. Biotechnology and Bioprocess Engineering, 22(5), 518-528. https:// doi.org/10.1007/s12257-017-0293-y

Li, Q., Wu, F., Wen, M., Yanagita, T., Xue, C., Zhang, T. and Wang, Y. (2018). The protective effect of Antarctic krill oil on cognitive function by inhibiting oxidative stress in the brain of senescenceaccelerated prone mouse strain 8 (SAMP8) mice. Journal of Food Science, 83(2), 543-551. https://doi.org/10.1111/1750-3841.14044

Liu, X., Cui, J., Leng, K., Xue, C., Li, Z., Xue, Y. and Wang, Y. (2016). Docosahexaenoic acid-enriched phospholipids exhibit superior effects on obesityrelated metabolic disorders to egg yolk phospholipids and soybean phospholipids in mice. European Journal of Lipid Science and Technology, 118(11), 1712-1721. https:// doi.org/10.1002/ejlt.201500552

Liu, X., Cui, J., Li, Z., Xu, J., Wang, J., Xue, C. and Wang, Y. (2014). Comparative study of DHAenriched phospholipids and EPA-enriched phospholipids on metabolic disorders in diet-induced -obese C57BL/6J mice. European Journal of Lipid Science and Technology, 116(3), 255-265. https:// doi.org/10.1002/ejlt.201300407

Liu, X., Xue, Y., Liu, C., Lou, Q., Wang, J., Yanagita, T., Xue, C. and Wang, Y. (2013). Eicosapentaenoic acid-enriched phospholipid ameliorates insulin resistance and lipid metabolism in diet-inducedobese mice. Lipids in Health and Disease, 12, 109. https://doi.org/10.1186/1476-511X-12-109

Lordan, R., Tsoupras, A. and Zabetakis, I. (2017). Phospholipids of animal and marine origin: 
Structure, function, and anti-inflammatory properties. Molecules, 22(11), $1964 . \mathrm{https} / / /$ doi.org/10.3390/molecules22111964

Mansour, S.Z., Moustafa, E.M., Hassan, A.A. and Thabet, N.M. (2017). Protective role of Krill oil against estrogen deficiency induced neurodegeneration in ovariectomized rats. Indian Journal of Experimental Biology, 55(5), 279-285.

Meirow, Y. and Baniyash, M. (2017). Immune biomarkers for chronic inflammation related complications in non-cancerous and cancerous diseases. Cancer Immunology, Immunotherapy, 66 (8), 1089-1101. https://doi.org/10.1007/s00262-0172035-6

Milte, C.M., Sinn, N. and Howe, P.R. (2009). Polyunsaturated fatty acid status in attention deficit hyperactivity disorder, depression, and Alzheimer's disease: towards an omega-3 index for mental health? Nutrition Reviews, 67(10), 573-590. https:// doi.org/10.1111/j.1753-4887.2009.00229.x

Murru, E., Banni, S. and Carta, G. (2013). Nutritional properties of dietary omega-3-enriched phospholipids. BioMed Research International, 2013, 965417. https://doi.org/10.1155/2013/965417

Nasopoulou, C., Karantonis, H.C., Perrea, D.N., Theocharis, S.E., Iliopoulos, D.G., Demopoulos, C.A. and Zabetakis, I. (2010). In vivo antiatherogenic properties of cultured gilthead sea bream (Sparus aurata) polar lipid extracts in hypercholesterolaemic rabbits. Food Chemistry, 120 (3), 831-836. https://doi.org/10.1016/ j.foodchem.2009.11.023

Nasopoulou, C., Nomikos, T., Demopoulos, C.A. and Zabetakis, I. (2007). Comparison of antiatherogenic properties of lipids obtained from wild and cultured sea bass (Dicentrarchus labrax) and gilthead sea bream (Sparus aurata). Food Chemistry, 100(2), 560 -567 . https://doi.org/10.1016/ j.foodchem.2005.09.074

Nasopoulou, C., Psani, E., Sioriki, E., Demopoulos, C.A. and Zabetakis, I. (2013). Evaluation of sensory and in vitro cardioprotective properties of sardine (Sardina pilchardus): The effect of grilling and brining. Scientific Research, 4(9), 940-949. https:// doi.org/10.4236/fns.2013.49122

Nasopoulou, C., Tsoupras, A.B., Karantonis, H.C., Demopoulos, C.A. and Zabetakis, I. (2011). Fish polar lipids retard atherosclerosis in rabbits by downregulating PAF biosynthesis and up-regulating PAF catabolism. Lipids in Health and Disease, 10, 213. https://doi.org/10.1186/1476-511X-10-213

O’Donnell, V.B., Rossjohn, J. and Wakelam, M.J.
(2018). Phospholipid signaling in innate immune cells. The Journal of Clinical Investigation, 128(7), 2670-2679. https://doi.org/10.1172/JCI97944

Parolini, C., Bjorndal, B., Busnelli, M., Manzini, S., Ganzetti, G.S., Dellera, F., Ramsvik, M., Bruheim, I., Berge, R.K. and Chiesa, G. (2017). Effect of dietary components from antarctic krill on atherosclerosis in apoE-deficient mice. Molecular Nutrition and Food Research, 61(12), 1700098. https://doi.org/10.1002/mnfr.201700098

Piscitelli, F., Carta, G., Bisogno, T., Murru, E., Cordeddu, L., Berge, K., Tandy, S., Cohn, J.S., Griinari, M., Banni, S. and Di Marzo, V. (2011). Effect of dietary krill oil supplementation on the endocannabinoidome of metabolically relevant tissues from high-fat-fed mice. Nutrition and Metabolism, 8, 51. https://doi.org/10.1186/17437075-8-51

Rossmeisl, M., Jilkova, Z.M., Kuda, O., Jelenik, T., Medrikova, D., Stankova, B., Kristinsson, B., Haraldsson, G.G., Svensen, H., Stoknes, I. and Sjövall, P. (2012). Metabolic effects of n-3 PUFA as phospholipids are superior to triglycerides in mice fed a high-fat diet: possible role of endocannabinoids. PloS One, 7(6), e38834. https:// doi.org/10.1371/journal.pone.0038834

Rossmeisl, M., Medrikova, D., Van Schothorst, E.M., Pavlisova, J., Kuda, O., Hensler, M., Bardova, K., Flachs, P., Stankova, B., Vecka, M. and Tvrzicka, E. (2014). Omega-3 phospholipids from fish suppress hepatic steatosis by integrated inhibition of biosynthetic pathways in dietary obese mice. Biochimica et Biophysica Acta (BBA)Molecular and Cell Biology of Lipids, 1841(2), 267278. https://doi.org/10.1016/j.bbalip.2013.11.010

Rundblad, A., Holven, K.B., Bruheim, I., Myhrstad, M.C. and Ulven, S.M. (2018). Effects of fish and krill oil on gene expression in peripheral blood mononuclear cells and circulating markers of inflammation: a randomised controlled trial. Journal of Nutritional Science, 7, e10. https:// doi.org/10.1017/jns.2018.2

Saini, R.K. and Keum, Y.S. (2018). Omega-3 and omega -6 polyunsaturated fatty acids: Dietary sources, metabolism, and significance-A review. Life Sciences, 203, 255-267. https://doi.org/10.1016/ j.lfs.2018.04.049

Sakakima, Y., Hayakawa, A., Nagasaka, T. Nakao, A. (2007). Prevention of hepatocarcinogenesis with phosphatidylcholine and menaquinone-4: in vitro and in vivo experiments. Journal of Hepatology, 47 (1), 83-92. https://doi.org/10.1016/ j.jhep.2007.01.030 
Su, X., Tanalgo, P., Bustos, M. and Dass, C.R. (2018). The effect of krill oil and n-3 polyunsaturated fatty acids on human osteosarcoma cell proliferation and migration. Current Drug Targets, 19(5), 479-486. https://

doi.org/10.2174/1389450116666150107152206

Sun, D., Zhang, L., Chen, H., Feng, R., Cao, P. and Liu, Y. (2017). Effects of Antarctic krill oil on lipid and glucose metabolism in C57BL/6J mice fed with high fat diet. Lipids in Health and Disease, 16(1), 218. https://doi.org/10.1186/s12944-017-0601-8

Tsoupras, A., Lordan, R. and Zabetakis, I. (2018). Inflammation, not cholesterol, is a cause of chronic disease. Nutrients, 10(5), $604 . \quad$ https:// doi.org/10.3390/nu10050604

Tsoupras, A., Lordan, R., Demuru, M., Shiels, K., Saha, S.K., Nasopoulou, C. and Zabetakis, I. (2018). Structural elucidation of irish organic farmed salmon (Salmo salar) polar lipids with antithrombotic activities. Marine Drugs, 16(6), 176. https:// doi.org/10.3390/md16060176

Tsoupras, A., Lordan, R., Shiels, K., Saha, S.K., Nasopoulou, C. and Zabetakis, I. (2019). In vitro antithrombotic properties of salmon (Salmo salar) phospholipids in a novel food-grade extract. Marine Drugs, 17(1), 62. https://doi.org/10.3390/ md17010062

Tsushima, T., Matsubara, K., Ohkubo, T., Inoue, Y. and Takahashi, K. (2012). Docosahexaenoic-and eicosapentaenoic acid-bound lysophospholipids are more effective in suppressing angiogenesis than conjugated docosahexaenoic acid. Journal of Oleo Science, 61(8), 427-432. https://doi.org/10.5650/ jos.61.427

Tuosto, L. and Xu, C. (2018). Membrane lipids in t Cell Functions. Frontiers in Immunology, 9, 1608. https:// doi.org/10.3389/fimmu.2018.01608

Varganova, D.L., Pavlov, C.S., Casazza, G., Nikolova, D. and Gluud, C. (2019). Essential phospholipids for people with non-alcoholic fatty liver disease. Cochrane Database of Systematic Review, 2019(4), CD013301. https:// doi.org/10.1002/14651858.CD013301

Vigerust, N.F., Bjørndal, B., Bohov, P., Brattelid, T., Svardal, A. and Berge, R.K. (2013). Krill oil versus fish oil in modulation of inflammation and lipid metabolism in mice transgenic for TNF- $\alpha$. European Journal of Nutrition, 52(4), 1315-1325. https:// doi.org/10.1007/s00394-012-0441-2

Wang, C.C., Wang, D., Zhang, T.T., Yanagita, T., Xue, C.H., Chang, Y.G. and Wang, Y.M. (2018). A comparative study about EPA-PL and EPA-EE on ameliorating behavioral deficits in MPTP-induced mice with Parkinson's disease by suppressing oxidative stress and apoptosis. Journal of Functional Foods, 50, 8-17. https://doi.org/10.1016/ j.jff.2018.09.027

Wang, C., Wang, D., Xu, J., Yanagita, T., Xue, C., Zhang, T. and Wang, Y. (2018). DHA enriched phospholipids with different polar groups (PC and PS) had different improvements on MPTP-induced mice with Parkinson's disease. Journal of Functional Foods, 45, 417-426. https://doi.org/10.1016/ j.jff.2018.04.017

Wang, D.D., Wu, F., Wen, M., Ding, L., Du, L., Xue, C.H., Xu, J. and Wang, Y.M. (2018). Replenishment of Docosahexaenoic Acid (DHA) in dietary n-3deficient mice fed DHA in triglycerides or phosphatidylcholines after weaning. Journal of Food Science, $\quad 83(2), \quad 481-488 . \quad$ https:// doi.org/10.1111/1750-3841.14017

Wen, M., Ding, L., Zhang, L., Zhou, M., Xu, J., Wang, J., Wang, Y. and Xue, C. (2016). DHA-PC and DHA -PS improved A $\beta 1-40$ induced cognitive deficiency uncoupled with an increase in brain DHA in rats. Journal of Functional Foods, 22, 417-430. https://doi.org/10.1016/j.jff.2016.02.004

Werner, K., de Gaudry, D.K., Taylor, L.A., Keck, T., Unger, C., Hopt, U.T. and Massing, U. (2017). Dietary supplementation with n-3-fatty acids in patients with pancreatic cancer and cachexia: marine phospholipids versus fish oil-a randomized controlled double-blind trial. Lipids in Health and Disease, 16, 104. https://doi.org/10.1186/s12944-017 $-0495-5$

Wibrand, K., Berge, K., Messaoudi, M., Duffaud, A., Panja, D., Bramham, C.R. and Burri, L. (2013). Enhanced cognitive function and antidepressant-like effects after krill oil supplementation in rats. Lipids in Health and Disease, 12, 6. https:// doi.org/10.1186/1476-511X-12-6

Wijendran, V., Huang, M.C., Diau, G.Y., Boehm, G., Nathanielsz, P.W. and Brenna, J.T. (2002). Efficacy of dietary arachidonic acid provided as triglyceride or phospholipid as substrates for brain arachidonic acid accretion in baboon neonates. Pediatric Research, 51(3), 265-272. https:// doi.org/10.1203/00006450-200203000-00002

Wu, F., Wang, D.D., Wen, M., Che, H.X., Xue, C.H., Yanagita, T., Zhang, T.T. and Wang, Y.M. (2017). Comparative analyses of DHA-Phosphatidylcholine and recombination of DHA-Triglyceride with EggPhosphatidylcholine or Glycerylphosphorylcholine on DHA repletion in n-3 deficient mice. Lipids in Health and Disease, 16, 234. https://doi.org/10.1186/ 
s12944-017-0623-2

Yamashita, S., Hashimoto, M., Haque, A.M., Nakagawa, K., Kinoshita, M., Shido, O. and Miyazawa, T. (2017). Oral administration of ethanolamine glycerophospholipid containing a high level of plasmalogen improves memory impairment in amyloid $\beta$-infused rats. Lipids, 52(7), 575-585. https://doi.org/10.1007/s11745-017-4260-3

Yang, Y.H., Wang, J.F., Long, T.T., Zhao, Q., Yang, Y.C., Ma, Q. and Xue, C.H. (2011). Role of docosahexaenoic acid-phosphatidylcholine liposomes in inhibiting tumor growth. Chinese Pharmacological Bulletin, 2.

Zabetakis, I. (2013). Food security and cardio protection: The polar lipid link. Journal of Food Science, 78(8), 1101-1104. https://doi.org/10.1111/1750-3841.12194

Zhang, J., Tao, N., Wang, M., Shi, W., Ye, B., Wang, X., Zhu, Q. and Hua, C. (2018). Characterization of phospholipids from Pacific saury (Cololabis saira) viscera and their neuroprotective activity. Food Bioscience, 24, 120-126. https://doi.org/10.1016/ j.fbio.2018.06.002

Zhang, M., Chi, X., Qu, N. and Wang, C. (2018). Long noncoding RNA lncARSR promotes hepatic lipogenesis via Akt/SREBP-1c pathway and contributes to the pathogenesis of nonalcoholic steatohepatitis. Biochemical and Biophysical Research Communications, 499(1), 66-70. https:// doi.org/10.1016/j.bbrc.2018.03.127

Zhang, T.T., Xu, J., Wang, Y.M. and Xue, C.H. (2019). Health benefits of dietary marine DHA/EPAenriched glycerophospholipids. Progress in Lipid Research, 75, 100997. https://doi.org/10.1016/ j.plipres.2019.100997

Zheng, W., Li, J., Wang, X., Yuan, Y., Zhang, J. and Xiu, Z. (2018). Effects of Antarctic krill docosahexaenoic acid on MCF-7 cell migration and invasion induced by the interaction of CD95 with caveolin-1. Life Sciences, 192, 270-277. https:// doi.org/10.1016/j.lfs.2017.11.011

Zheng, W., Wang, X., Cao, W., Yang, B., Mu, Y., Dong, Y. and Xiu, Z. (2017). E-configuration structures of EPA and DHA derived from Euphausia superba and their significant inhibitive effects on growth of human cancer cell lines in vitro. Prostaglandins, Leukotrienes and Essential Fatty Acids, 117, P47P53. https://doi.org/10.1016/j.plefa.2017.01.005

Zhou, M.M., Che, H.X., Huang, J.Q., Zhang, T.T., Xu, J., Xue, C.H. and Wang, Y.M. (2018). Comparative study of different polar groups of EPA-Enriched phospholipids on ameliorating memory loss and cognitive deficiency in aged SAMP8 Mice. Molecular Nutrition and Food Research, 62
(7), 1700637

mnfr.201700637 https://doi.org/10.1002/

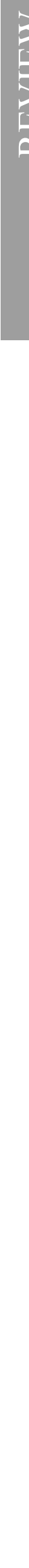

.

